\title{
The Switch from Fetal to Adult Hemoglobin
}

\author{
Vijay G. Sankaran ${ }^{1,2,3}$ and Stuart H. Orkin ${ }^{1,4,5}$ \\ ${ }^{1}$ Division of Hematology/Oncology, Children's Hospital Boston, Harvard Medical School, Boston, \\ Massachusetts 02115 \\ ${ }^{2}$ Whitehead Institute for Biomedical Research, Cambridge, Massachusetts 02142 \\ ${ }^{3}$ Broad Institute, Cambridge, Massachusetts 02142 \\ ${ }^{4}$ Dana-Farber Cancer Institute, Boston, Massachusetts 02115 \\ ${ }^{5}$ Howard Hughes Medical Institute, Boston, Massachusetts 02115 \\ Correspondence: sankaran@broadinstitute.org; stuart_orkin@dfci.harvard.edu
}

The fetal-to-adult hemoglobin switch and silencing of fetal hemoglobin ( $\mathrm{HbF}$ ) have been areas of long-standing interest among hematologists, given the fact that clinical induction of $\mathrm{HbF}$ production holds tremendous promise to ameliorate the clinical symptoms of sickle cell disease (SCD) and $\beta$-thalassemia. In this article, we discuss historic attempts to induce $\mathrm{HbF}$ that have resulted in some therapeutic approaches to manage SCD and $\beta$-thalassemia. We then go on to discuss how more recent molecular studies that have identified regulators, including BCL11A, MYB, and KLF1, hold great promise to develop targeted and more effective approaches for $\mathrm{HbF}$ induction. We go on to discuss strategies by which such approaches may be developed. Older studies in this field can provide important lessons for future studies aimed at developing more effective strategies for $\mathrm{HbF}$ induction, and we therefore chronologically cover the work accomplished as this field has evolved over the course of the past four decades.

\begin{abstract}
$A$ with many facets of the history of the heAmoglobin field, the study of the fetal-toadult hemoglobin switch and work on fetal hemoglobin silencing has a rich and storied history that spans the course of several decades. In this work, we begin with a historic overview of this field and then move on to discuss more recent molecular findings that are providing important new insight into this process. There is great hope that these new molecular studies may lead to important targeted therapeutic advances for fetal hemoglobin (HbF) induction. However, the historic work in this field suggests that
\end{abstract}

the road to effective therapies may not always be straightforward and reconsidering seemingly simple observations can often yield important new insights. There are many valuable lessons that can be learned from both the historic and more recent work in this field and therefore we attempt to cover the chronology of findings that have resulted in our current understanding of the fetal-to-adult hemoglobin switch.

The disorders of $\beta$-hemoglobin, sickle cell disease (SCD) and $\beta$-thalassemia, are major sources of morbidity and mortality worldwide (Weatherall et al. 2006). These diseases are the

Editors: David Weatherall, Alan N. Schechter, and David G. Nathan

Additional Perspectives on Hemoglobin and Its Diseases available at www.perspectivesinmedicine.org

Copyright (C) 2013 Cold Spring Harbor Laboratory Press; all rights reserved; doi: 10.1101/cshperspect.a011643

Cite this article as Cold Spring Harb Perspect Med 2013;3:a011643 
most common genetic disorders in the world. It is currently estimated that at least 300,000 children with these diseases are born every year, giving rise to a worldwide population of tens of millions of patients with these diseases (Weatherall et al. 2006). With the epidemiological transition that most developing countries are currently undergoing-with significant decreases in mortality from infectious and nutritional causes - there will likely be an increase in the prevalence of these diseases in the ensuing years. Therefore, developing improved therapies for these disorders will be of paramount importance for this important global health burden.

In SCD, a single base substitution causes a missense mutation of a valine for glutamic acid at amino acid six of the $\beta$-globin protein chain, which leads to a propensity of the sickle hemoglobin to polymerize. This in turn results in deformation of erythrocytes containing this hemoglobin, which can block small blood vessels, leading to impaired oxygen delivery to tissues. This can result in significant clinical complications including pain crises, respiratory complications, and organ damage. In $\beta$-thalassemia, insufficient production of the $\beta$-globin molecule results in an excess of unpaired $\alpha$-globin chains that can precipitate within erythroid precursors. The precipitation of these free $\alpha$-globin chains impairs the maturation and leads to death of these precursors, causing ineffective production of erythroid cells. As a result, a significant anemia occurs and the consequent expansion of erythroid precursors can lead to secondary problems in bones and other organs.

The only potentially curative therapies that are available for these diseases are bone marrow transplantation (Michlitsch and Walters 2008) and gene therapy (Persons 2009), but there are numerous challenges that exist to implement these treatments and they have significant limitations for widespread use, particularly in the developing world (Sankaran and Nathan 2010b). These curative therapies still remain largely experimental, although important scientific and clinical advances in these approaches are being made (Hsieh et al. 2009; Cavazzana-Calvo et al. 2010). Currently, the major treatment for these disorders involves symptomatic care and transfusion of red blood cells as clinically necessary. However, the use of regular blood transfusions can lead to significant problems. Most notably, iron overload can lead to major clinical complications, even when the strictest iron chelation regimens are used (Porter and Shah 2010).

\section{THE FETAL-TO-ADULT GLOBIN SWITCH}

The hemoglobin molecule is a tetramer composed of two subunits of $\alpha$-like globin peptide chains and two subunits of the $\beta$-like globin peptides, along with heme moieties necessary for this molecule's oxygen-carrying capacity. A variety of $\beta$-like globin molecules are produced as a result of the fact that the human $\beta$-globin locus on chromosome 11 is developmentally regulated (Fig. 1) (Sankaran and Nathan 2010a; Sankaran et al. 2010). In the early part of the first trimester, there is robust expression of an embryonic form of a $\beta$-like globin known as $\varepsilon$-globin within the yolk sac-derived primitive lineage of erythrocytes (Peschle et al. 1985). Soon thereafter, when production of the first enucleated definitive erythrocytes commences from stem and progenitor cells in the fetal liver (McGrath and Palis 2008), the predominant $\beta$-like globin molecule produced is $\gamma$-globin (Sankaran et al. 2010). This molecule is encoded by two duplicated $\gamma$-globin genes found within the $\beta$-globin gene cluster (Fig. 1). The $\gamma$-globin chains combine with adult $\alpha$-globin chains into a stable tetramer forming $\mathrm{HbF}$. This remains the predominant hemoglobin for much of gestation. Shortly after the time of birth there is a switch from predominant expression of $\mathrm{HbF}$ to adult hemoglobin ( $\mathrm{HbA})$, which is mediated by a transcriptional switch in definitive erythroid progenitors from $\gamma$ - to $\beta$-globin (Fig. 1).

Avariety of clinical observations have shown that the severity of SCD and $\beta$-thalassemia is ameliorated via increased production of $\mathrm{HbF}$. Children with SCD were noted to be asymptomatic until after infancy, which was postulated to be attributable to elevated fetal hemoglobin (HbF) levels (Watson 1948). This notion was substantiated by observations of rare patients with compound heterozygosity for sickle cell 


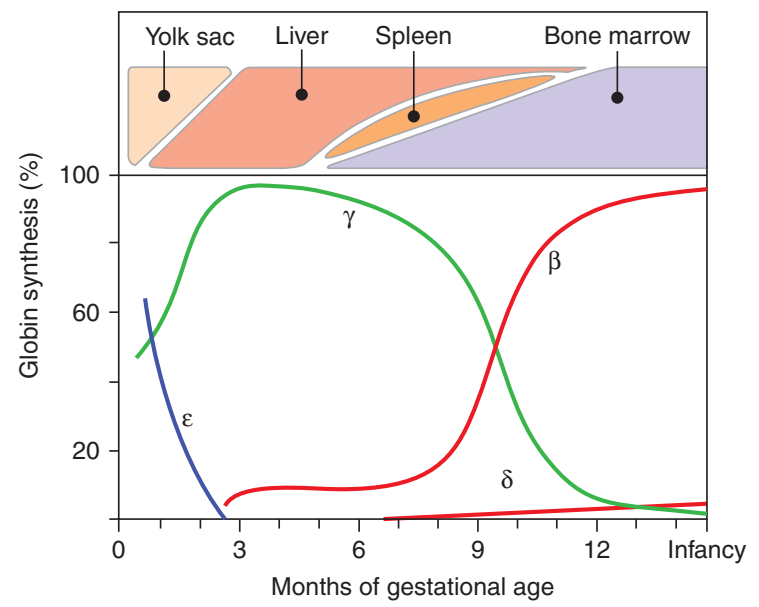

$\beta$-Globin locus

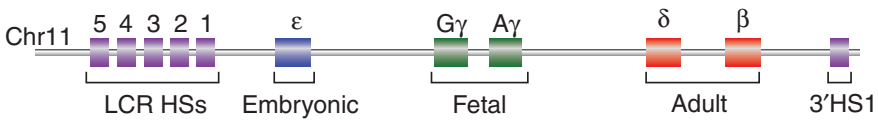

Figure 1. The fetal-to-adult hemoglobin switch. This illustration depicts the normal timing of the developmental hemoglobin switches in humans. In the top panel, the sites and levels of various $\beta$-like globin molecules are shown with colors corresponding to the various developmental groups of genes shown below it in a model of the human $\beta$-globin locus (embryonic in blue, fetal in green, and adult in red). The bottom illustration also depicts the upstream enhancer of the $\beta$-globin locus, known as the locus control region (LCR), with its corresponding DNAse I hypersensitivity sites (HSs) and a downstream HS known as the $3^{\prime} \mathrm{HS} 1$.

disease and hereditary persistence of fetal hemoglobin (HPFH) mutations, who were largely asymptomatic (Weatherall and Clegg 2001). Moreover, certain populations of patients with SCD, such as those from parts of Saudi Arabia and India, had unusually high levels of $\mathrm{HbF}$ associated with a less symptomatic clinical course (Perrine et al. 1972; Kar et al. 1986; Weatherall and Clegg 2001). These observations were subsequently confirmed with larger epidemiological studies in SCD, which showed that increased $\mathrm{HbF}$ levels can significantly and quantitatively ameliorate the clinical severity and decrease mortality in SCD (Platt et al. 1991, 1994; Castro et al. 1994). Similar observations have been made in patients with $\beta$-thalassemia. Clinical observations in rare $\beta$-thalassemia patients with elevated production of $\mathrm{HbF}$ showed that these increased levels resulted in a milder clinical course and infants with $\beta$-thalassemia only begin to show symptoms after the expression of $\mathrm{HbF}$ declines in the months following birth
(Weatherall 2001; Weatherall and Clegg 2001). Larger epidemiological studies of thalassemia populations have confirmed such findings (Premawardhena et al. 2005; Galanello et al. 2009; Nuinoon et al. 2010). While it has been difficult to tease apart the extent to which increased $\mathrm{HbF}$ production can ameliorate symptoms in thalassemia because it is difficult to ascertain the extent of $\gamma$-globin production directly in patients with the need for frequent blood transfusions and such a great extent of ineffective erythropoiesis, a recent analysis in untransfused patients with $\beta$-thalassemia shows the quantitative ameliorating effect of $\mathrm{HbF}$ levels on clinical severity in this disease as well (Musallam et al. 2011).

\section{EARLY MOLECULAR STUDIES LEAD TO THERAPEUTIC APPROACHES FOR HbF INDUCTION}

Given the variety of robust clinical observations demonstrating the ability of $\mathrm{HbF}$ to ameliorate 
the severity of both SCD and $\beta$-thalassemia, there has been a long-standing interest in devising therapeutic approaches to stimulate the production of this beneficial form of hemoglobin. With the advent of molecular biology, the cloning of the globin genes and mapping of the entire $\beta$-globin gene cluster became a reality (Fig. 1) (Fritsch et al. 1980; Sankaran and Nathan 2010b). In the course of this work, it was noted that the $\gamma$-globin genes underwent DNA methylation when silenced in adult erythroid progenitors, while not having DNA methylation present when transcriptionally active in fetal erythroid progenitor cells (van der Ploeg and Flavell 1980). Around this time, the DNA methylation inhibitor 5-azacytidine was first being characterized and was shown to have potent activity to reverse DNA methylation in a variety of mammalian cell types (Jones and Taylor 1980; Groudine et al. 1981). Given the similarity in the regulation of the primate $\beta$-globin gene cluster compared with that of humans, 5-azacytidine was tested and showed a potent ability to induce the silenced $\gamma$-globin genes in adult erythroid cells of primates (DeSimone et al. 1982). This led to small clinical trials of 5-azacytidine in patients with SCD and $\beta$-thalassemia in which robust responses were initially seen in the ability of this molecule to stimulate $\mathrm{HbF}$ production and reduce clinical markers of disease (Ley et al. 1982, 1983). There was great hope and promise that this would lead to a broadly applicable targeted molecular approach for HbF induction (Benz 1982), but there was significant concern over the mutagenic potential of 5-azacytidine.

Soon after this work was performed, a number of investigators began to question whether the HbF-inductive activity of 5-azacytidine may be directly attributable to its DNA demethylating activity or whether its activity as a cell-cycle inhibitor, specifically an S-phase inhibitor, may play a role in this activity. As a result, a number of S-phase inhibitors that had varying mechanisms of action were tested and nearly all of these compounds showed robust activity at inducing $\mathrm{HbF}$ in primate models (Letvin et al. 1984, 1985; Papayannopoulou et al. 1984). This led to small clinical trials with the safest of these compounds, hydroxyurea, in SCD patients in which HbF-inductive effects were observed (Platt et al. 1984; Platt 2008). Subsequent clinical trials showed that treatment with hydroxyurea could ameliorate clinical symptoms in SCD (Charache et al. 1995; Steinberg et al. 2003; Platt 2008) leading to its FDA approval for the management of adult patients with SCD. The exact molecular mechanisms by which hydroxyurea is able to induce $\mathrm{HbF}$ are still poorly understood (Platt 2008) and much more work is needed to both investigate these mechanisms and to further investigate whether hydroxyurea or other S-phase inhibitors may be useful as therapeutic agents in $\beta$-thalassemia.

Around the same period of time, it was shown that infants of diabetic mothers have a delayed fetal-to-adult hemoglobin switch (Bard and Prosmanne 1985; Perrine et al. 1985). Because it was known that $\beta$-hydroxybutyrate is elevated in these diabetic mothers, a series of experiments was performed to test whether butyrate or other similar short-chain fatty acids may be effective as inducers of HbF. Although initial trials showed promise (Perrine et al. 1993, 1994), these therapies did not show consistent effectiveness in larger clinical trials (Sher et al. 1995; Sankaran and Nathan 2010b). It should be noted nonetheless that a subset of patients did show responses in these trials (Sher et al. 1995; Sankaran and Nathan 2010b). However, additional concerns were raised over possible toxic side effects and the difficulty in delivery of these medications, which limited further clinical trials and drug development efforts. It has been suggested that these short-chain fatty acids are likely to induce $\mathrm{HbF}$ through the inhibition of histone deacetylases (HDACs) (Fathallah et al. 2007). A variety of HDAC inhibitors are potent inducers of $\mathrm{HbF}$ in vitro and further work is needed to study these molecules (Cao et al. 2004; Atweh and Fathallah 2010; Bradner et al. 2010). Although the majority of studies have been focused on nonspecific HDAC inhibitors, recent work suggests that inhibitors of specific HDACs, such as HDAC 1 and 2, may allow improved efficacy of $\mathrm{HbF}$ induction while potentially minimizing toxicity (Bradner et al. 2010). 


\section{THE PROMISE OF IMPROVED THERAPIES THROUGH MOLECULAR STUDIES OF FETAL HEMOGLOBIN REGULATION}

Although the nontargeted therapeutic approaches discussed above have shown promise and some success at inducing $\mathrm{HbF}$ in clinical settings, an improved mechanistic understanding of the molecular underpinnings necessary for the normal fetal-to-adult hemoglobin switch holds great promise for allowing more effective and specifically targeted approaches for $\mathrm{HbF}$ induction to be developed. In the decades following the molecular cloning of the globin genes, a variety of transcription factors that played roles in globin gene regulation were identified (Cantor and Orkin 2002). This included transcription factors such as GATA1, KLF1, and SCL/ TAL1. However, studying the role of these factors in globin gene regulation was confounded by the broad role of these factors in differentiation and their pleiotropic roles as regulators of globin and erythroid gene regulation. None of these factors appeared to be specific regulators of the fetal-to-adult hemoglobin switch. It took nearly three decades from the initial cloning of the globin genes before specific regulators of this process would be identified.

Important clues into the identity of such factors came about from the study of natural human genetic variation. A number of groups pursued the basis for common genetic variation in $\mathrm{HbF}$ levels using both targeted and genome-wide association studies (GWAS) (Menzel et al. 2007; Thein et al. 2007; Lettre et al. 2008; Uda et al. 2008). These studies resulted in the identification of three genomic loci harboring common variants that influenced $\mathrm{HbF}$ levels. This included a region of chromosome 2 within the BCL11A gene, a region intergenic between the genes $H B S 1 L$ and MYB on chromosome 6, and variants within the $\beta$-globin locus on chromosome 11 . Recent studies that have more finely mapped these genetic variants suggest that $>50 \%$ of the variation in HbF levels may be explained by commonvariation at these three loci (Galarneau et al. 2010). Although HbF levels are thought to have a heritable genetic component in the range of $\sim 80 \%$, it is important to bear in mind that the additive genetic variation found from common genetic variants ignores potential higher-order genetic interactions that may not be detected and therefore the extent to which $\mathrm{HbF}$ levels are genetically determined remains to be explored in future studies (Zuk et al. 2012).

The initial observation of variants associated with $\mathrm{HbF}$ levels within the zinc-finger transcription factor BCL11A led to an initial study that pursued the hypothesis that BCL11A may be a regulator of $\mathrm{HbF}$ expression (Sankaran et al. 2008). Previous work had suggested that BCL11A was a critical transcriptional regulator involved in B lymphopoiesis and neurogenesis (Sankaran et al. 2010). BCL11A protein levels appeared to correlate with the developmental stage of expression, such that primitive and fetal liver definitive erythroid cells that expressed high levels of $\gamma$-globin, had low or absent expression of the full-length forms of BCL11A. This result suggested that this gene product was acting as a repressor of the $\gamma$-globin genes. To directly test this, knockdown of BCL11A using short-hairpin RNA (shRNA) approaches was performed in primary adult erythroid progenitors and $\gamma$-globin expression could be robustly induced on such a knockdown. The degree of $\gamma$ globin induction appeared to be related to the extent of knockdown of BCL11A. Interestingly, major perturbations in erythropoiesis did not appear to occur despite the robust $\gamma$-globin induction seen. Follow-up studies have shown similar results when knocking down the expression of BCL11A using shRNAs (Borg et al. 2010; Zhou et al. 2010; Wilber et al. 2011). It was additionally shown that BCL11A directly interacts with chromatin at the human $\beta$-globin locus in primary erythroid cells and that it appeared to act as part of a complex with the transcription factor GATA1 and the NuRD chromatin remodeling and repressor complex (Sankaran et al. 2008). Of interest, the NuRD complex contains HDACs 1 and 2, which have been suggested to be the critical HDACs necessary for HbF silencing (Bradner et al. 2010). In addition, it has been suggested that the transcription factor SOX6 may cooperate with BCL11A to help silence the $\gamma$-globin genes in humans and it may be essential for binding 
the proximal promoter of these globin genes (Xu et al. 2010).

Although hemoglobin switching in mouse models, even those harboring a human $\beta$-globin locus transgene, appears to diverge from the normal ontogeny of globin expression seen in humans, an evolutionarily conserved role of BCL11A in globin gene silencing and switching was shown in mice (Sankaran et al. 2009; McGrath et al. 2011). Mice lacking BCL11A appear to have normal erythropoiesis, but fail to fully silence the embryonic globin genes in definitive erythroid cells and allow some persistent expression of $\gamma$-globin when the intact human $\beta$-globin locus is present. These findings reinforce the importance of BCL11A as a critical mediator of globin switching in mammals. Although this initial study addressed the role of BCL11A in the developmental process of globin switching in mice (Sankaran et al. 2009), a more recent study used conditional inactivation of BCL11A to show that inducible inactivation can result in robust and similar extents of $\gamma$-globin gene induction as occurs when inactivation occurs at earlier time points (Xu et al. 2011). Moreover, although there is differential regulation of the globin genes between humans and mice, inactivation of BCL11A was shown to be sufficient to ameliorate the hematological and pathological features seen in mouse models of sickle cell disease, providing an important proof of principal for the potential efficacy of targeting BCL11A to induce $\mathrm{HbF}$ (Xu et al. 2011).

The exact mechanisms by which BCL11A silences $\gamma$-globin gene expression remain unclear. A recent study suggests that this may be mediated through both interactions with transcription factors, such as SOX6 that bind chromatin at the proximal $\gamma$-globin promoters, as well as through long-range interactions with a variety of regions throughout the $\beta$-globin gene cluster (Xu et al. 2010). When BCL11A is absent, the conformation of the $\beta$-globin locus changes such that the upstream enhancer known as the locus control region is juxtaposed with the transcriptionally activated $\gamma$-globin genes. A similar phenomenon occurs when cells are treated with HDAC inhibitors that induce $\gamma$-globin gene expression (Bradner et al. 2010). However, it is unclear if these conformational alterations are directly mediated by BCL11A or if these alterations occur secondarily to the HbF-inductive effect of BCL11A (or HDAC) inhibition. Nonetheless, these findings strongly support the notion that BCL11A appears to have a direct role in silencing $\gamma$-globin expression within the $\beta$ globin locus. By mapping a variety of deletions within the human $\beta$-globin locus that either result in $\delta \beta$-thalassemia, with modest increases in $\mathrm{HbF}$ and some remaining globin chain imbalance present, or HPFH, with robust increases in $\mathrm{HbF}$ and balanced globin chain synthesis, it was shown that an N3-kb region upstream of the $\delta$-globin gene is necessary for silencing of the $\gamma$-globin genes (Fig. 2) (Sankaran et al. 2011c). Interestingly, this region harbors binding sites for BCL11A, along with its partners such as GATA1 and HDAC1. Of note, this region has also been independently implicated as being important for $\gamma$-globin silencing through studies of the Corfu thalassemia deletion in humans (Chakalova et al. 2005). This study provides important mechanistic insight about how BCL11A functions to silence $\mathrm{HbF}$ and reinforces the importance of natural human mutations in understanding this developmental process that is unique to humans (Fig. 2) (Sankaran et al. 2011c).

Given these findings, BCL11A is likely to be an important therapeutic target. The fact that its inactivation induces $\mathrm{HbF}$ without resulting in a major perturbation in erythropoiesis is very promising, although it is known to have important effects in other lineages such as B lymphocytes, stressing the importance of in vivo modeling and analysis as part of ongoing efforts to target BCL11A for $\mathrm{HbF}$ induction. Further studies exploring the mechanisms of action by which BCL11A functions could lead to better and more specifically targeted approaches for HbF induction (Sankaran et al. 2011c). SOX6 may also be a potentially promising target for $\mathrm{HbF}$ induction (Xu et al. 2010), although it is known to be necessary for normal erythropoiesis (Dumitriu et al. 2006). However, a patient has been reported with a heterozygous disruption of SOX6 who did not have elevated $\mathrm{HbF}$ levels, suggesting that the SOX6 gene may have a 


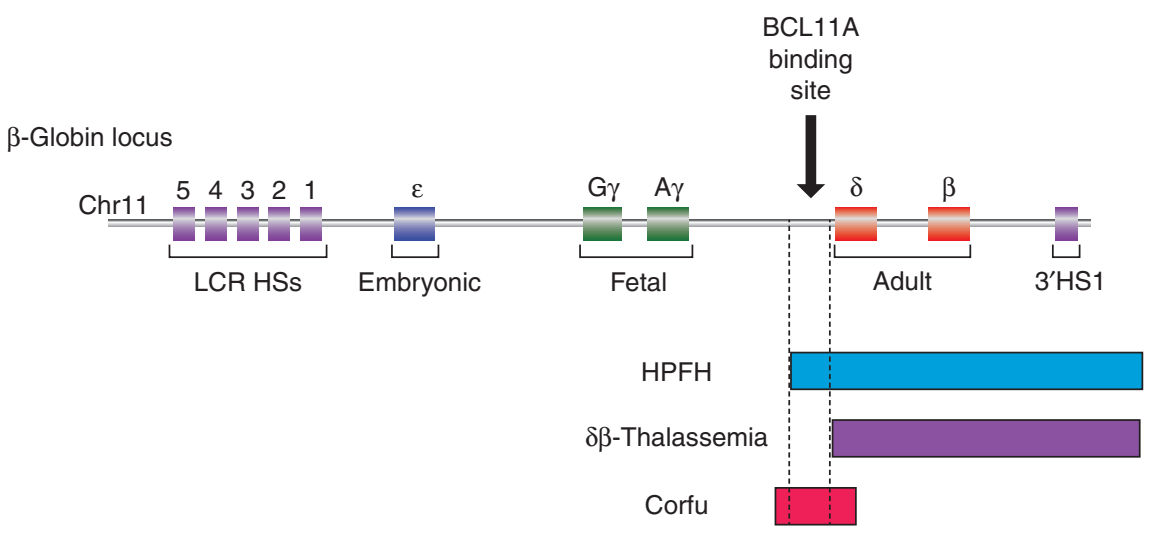

Figure 2. A model for regulation of $\gamma$-globin silencing in the human $\beta$-globin locus. This illustration depicts the human $\beta$-globin locus as shown in Figure 1 with an $\sim 3$-kb region upstream of the $\delta$-globin gene that was found by comparing the regions removed in various hereditary persistence of fetal hemoglobin (HPFH) deletions with the regions removed by $\delta \beta$-thalassemia deletions (Sankaran et al. 2011c). Typical deletions are illustrated in the model below the locus. In addition, the Corfu thalassemia deletion is also known to remove this region, as shown by the model below. BCL11A has been shown to bind to chromatin within this 3-kb region, along with its partners GATA1 and HDAC1 (Sankaran et al. 2011c).

mechanism for dosage compensation or that there may be a particular threshold necessary for reducing expression of this gene to have robust HbF induction (Sankaran et al. 2011a). This suggests that there may be limitations in considering SOX6 as a potential $\mathrm{HbF}$ induction target.

Following the initial studies on BCL11A, two studies suggested that the expression of BCL11A appears to be controlled by the erythroid specific transcription factor KLF1 using independent and complimentary approaches. In one study, a mouse with a hypomorphic allele of KLF1 resulted in elevations of embryonic globin expression and transgenic mice with the human $\beta$-globin locus showed persistent expression of $\gamma$-globin (Zhou et al. 2010). As a result, the investigators tested whether the same regulation could occur in primary human erythroid cells and could show a similar connection using shRNA approaches. The investigators then showed that this effect occurs through both direct effects of KLF1 at the $\beta$-globin locus, but also via indirect effects mediated through reduced expression of $B C L 11 A$ on KLF1 knockdown. This finding showed that KLF1 was a direct positive transcriptional regulator of $B C L 11 A$ expression. A second group examined the genetic basis of an unlinked form of HPFH that was suggested to result from a KLF1 missense mutation in this family (Borg et al. 2010). The investigators could show, using primary cells from these patients and from unaffected controls, that the effect seen was in part attributable to a silencing effect of KLF1 on $B C L 11 A$. One area of ongoing uncertainty relates to the human phenotypes seen with various cases of KLF1 mutations. Although in the initial report, all recipients of the missense mutation had elevations in $\mathrm{HbF}$ expression, it should be noted that this actually varied between $3 \%$ and $19 \%$ of total hemoglobin levels. In addition, other reports of heterozygous KLF1 mutations in humans either show concomitant disruption of erythropoiesis or show little effect on HbF expression (Arnaud et al. 2010; Satta et al. 2011). More recent studies suggest that rare variants in $K L F 1$ are indeed associated with elevations in $\mathrm{HbF}$, but this does not appear to occur consistently or to the same extent even with similar mutations (Gallienne et al. 2012). The basis of this variation remains to be determined and will be important to better understand the mechanisms by which KLF1 acts both directly and indirectly, to affect $\mathrm{HbF}$ expression. This will be critical for any future work attempting to target KLF1 for HbF induction, particularly if the 
untoward effects of such inhibition on erythroid differentiation are to be avoided. However, given the specificity of KLF1 within the erythroid lineage and if the globin gene regulating activity of KLF1 could be specifically targeted, it should still be considered a candidate for inducing $\mathrm{HbF}$.

In addition to the common genetic variants identified in BCL11A associated with HbF levels in humans, the GWAS studies showed that there were variants on chromosome 6 intergenic between the genes HBS1L and MYB that appear to have a dramatic effect on HbF levels in humans (Menzel et al. 2007; Thein et al. 2007; Lettre et al. 2008; Uda et al. 2008). Understanding the mechanism of action by which these variants result in alterations in HbF levels is important, as the genetic variants at this locus appear to have as great or perhaps even a greater effect on clinical morbidity in the $\beta$-hemoglobinopathies as those variants at the BCL11A locus (Galanello et al. 2009; Nuinoon et al. 2010). Interestingly, this region contains a variety of regulatory elements that have been suggested to have an important role in regulating expression of MYB in erythroid progenitors (Mukai et al. 2006; Wahlberg et al. 2009; Stadhouders et al. 2011). Although overexpression of HBS1L did not appear to effect $\gamma$-globin expression in K562 erythroleukemia cells, overexpression of MYB did appear to affect the level of $\gamma$-globin produced in these cells (Jiang et al. 2006). Moreover, cultures of primary erythroid progenitors from humans with higher expression of $\mathrm{HbF}$ more often had decreased expression of $M Y B$ (Jiang et al. 2006).

By following up on the classic clinical observation that patients with a trisomy of chromosome 13 have a delayed fetal-to-adult hemoglobin switch and continue to have persistent expression of HbF (Huehns et al. 1964; Sankaran and Sapp 2012), recent studies have provided further evidence for a role of $M Y B$ in regulating $\mathrm{HbF}$ expression. By fine mapping and performing integrative genomic analysis of genes in a region on chromosome 13 implicated as being necessary for the elevation of $\mathrm{HbF}$ seen in patients with partial trisomies of chromosome 13 , it was found that there were two small $\sim 22$ nucleotide RNA molecules that were top candidates to carry out such an activity, microRNAs 15a and 16-1 (Sankaran et al. 2011b). Overexpression of these microRNAs in primary adult erythroid cells in culture resulted in increases in $\gamma$-globin production. By examining targets of these microRNAs, it was noted that one major target in erythroid cells was $M Y B$. Direct knockdown of $M Y B$ in primary adult erythroid progenitors resulted in dramatic increases in $\gamma$-globin production (Sankaran et al. 2011b), connecting this historic observation from a rare human aneuploidy syndrome to the more recent work examining molecular mechanisms regulating $\mathrm{HbF}$ levels.

The mechanism by which MYB may act to regulate $\mathrm{HbF}$ levels remains unclear. This may be owing to an effect on the kinetics of erythropoiesis or alternatively may also occur as a result of a direct effect within the $\beta$-globin locus (Higgs and Wood 2008). Further work will be necessary to explore such mechanisms and hold great promise in attempts to therapeutically target this molecule for $\mathrm{HbF}$ induction. There is concern that targeting of $M Y B$ could have undesirable side effects, particularly given the pleiotropic role of MYB in hematopoiesis (Emambokus et al. 2003; Carpinelli et al. 2004). However, recent work suggests that such strategies may actually hold promise, because partial knockdown of $M y b$ in mice had little effect on normal in vivo hematopoiesis while dramatically blocking progression of leukemias (Zuber et al. 2011a). Therefore, partial inhibition of $M Y B$ may hold promise as a valuable strategy for $\mathrm{HbF}$ induction. The additivity of the effects of variants in the $H B S 1 L-M Y B$ intergenic region along with variants at the BCL11A locus (Lettre et al. 2008; Galanello et al. 2009; Nuinoon et al. 2010) suggests that targeting both of these pathways together could yield even more robust effects than targeting either pathway alone.

Although the regulators of $\mathrm{HbF}$ regulation discussed above have been found through human genetic studies, thus confirming their in vivo relevance in humans, a variety of other molecules have also been suggested to play roles in $\gamma$-globin gene regulation through various studies using cell culture approaches or with mouse models (Table 1). These molecules will 
be discussed below. It is important to bear in mind that there are limitations for most of the currently available experimental systems used to study $\gamma$-globin gene regulation. Primary human erythroid cells seem to be permissive to manipulation that will allow increases in $\gamma$-globin production, which may not always be relevant in humans in vivo. In addition, many of the stimuli that are known to induce $\gamma$-globin production in vivo in humans, including various types of stress erythropoiesis and treatment with hydroxyurea, do not function to induce $\gamma$-globin production in humanized mouse models (Pace et al. 1994; Sankaran et al. 2009) stressing an important limitation for interpreting negative findings in this experimental system. Thus, caution needs to be exercised when interpreting experimental findings not supported by evidence from human genetic studies or studies performed in humans or primates in vivo.

By examining proteins that bind the direct repeat elements found within the promoter of the $\gamma$-globin genes, the orphan nuclear hormone receptors TR2 and TR4 have been suggested to play a role as repressors of the expression of the $\gamma$-globin genes (Tanabe et al. 2002, 2007; Cui et al. 2011). Paradoxically, overexpression of TR2 and TR4 in transgenic mouse models results in elevated expression of $\gamma$-globin and when overexpressed in sickle cell disease mouse models can result in partial amelioration of he- matologic and pathologic symptoms of these mice (Campbell et al. 2011). The mechanisms underlying these observations and the relevance to human globin gene regulation remains to be established for TR2 and TR4. In addition, the orphan nuclear hormone nuclear receptor COUP-TFII has also been suggested to bind to the direct repeats and repress the $\gamma$-globin promoter in humans (Filipe et al. 1999). Using in vitro cultures of primary adult erythroid cells, it was shown that cytokines such as SCF appear to down-regulate expression and chromatin occupancy of COUP-TFII at the $\beta$-globin locus, resulting in increased $\gamma$-globin expression (Aerbajinai et al. 2009). Moreover, direct down-regulation of COUP-TFII using small interfering RNAs (siRNAs) could result in increases in $\gamma$ globin production (Aerbajinai et al. 2009). Further studies on the role of COUP-TFs in the regulation of $\mathrm{HbF}$ will be needed to better understand its physiologic role in humans.

Recent studies have also suggested a role for the gene named friend of PRMT1 (FOP1) in repression of $\gamma$-globin gene expression (van Dijk et al. 2010). Knockdown of FOP1 results in elevated $\mathrm{HbF}$ expression in human adult erythroid cells in culture. It was suggested that this was mediated through reduced expression of SOX6, knockdown of which is known to also result in increases in $\gamma$-globin production (Xu et al. 2010). Further work will be needed to

Table 1. A partial list of fetal hemoglobin regulators

\begin{tabular}{|c|c|c|c|c|c|}
\hline Regulator & $\begin{array}{c}\text { Direction of } \\
\text { modulation } \\
\text { needed to } \\
\text { increase HbF }\end{array}$ & $\begin{array}{l}\text { Human genetic } \\
\text { evidence } \\
\text { supporting role } \\
\text { in HbF regulation }\end{array}$ & $\begin{array}{c}\text { Human or primate } \\
\text { studies modulating } \\
\text { factor involved in } \\
\text { HbF regulation }\end{array}$ & $\begin{array}{l}\text { Cell culture data } \\
\text { supporting a } \\
\text { role in } \mathrm{HbF} \\
\text { regulation }\end{array}$ & $\begin{array}{c}\text { Evidence from } \\
\text { mouse models } \\
\text { suggesting a role } \\
\text { in HbF regulation }\end{array}$ \\
\hline BCL11A & $\downarrow$ & $\times$ & & $\times$ & $\times$ \\
\hline KLF1 & $\downarrow$ & $\times$ & & $\times$ & $\times$ \\
\hline MYB & $\downarrow$ & $\times$ & & $x$ & \\
\hline $\begin{array}{c}\text { MicroRNAs } \\
15 \mathrm{a} / 16-1\end{array}$ & $\uparrow$ & $\times$ & & $x$ & \\
\hline SOX6 & $\downarrow$ & & & $\times$ & \\
\hline HDACs $1 / 2$ & $\downarrow$ & & $\times$ & $x$ & $\times$ \\
\hline DNMT1 & $\downarrow$ & & $\times$ & $\times$ & $\times$ \\
\hline TR2/TR4 & $\downarrow$ or $\uparrow$ & & & $x$ & $\times$ \\
\hline COUP-TFII & $\downarrow$ & & & $x$ & \\
\hline FOP & $\downarrow$ & & & $\times$ & \\
\hline NF-E4 & $\uparrow$ & & & $\times$ & \\
\hline
\end{tabular}


confirm these findings, understand whether this gene also has a role in erythropoiesis more broadly, and examine the mechanism underlying these observations.

Some studies have also suggested a role for the stage-selector protein NF-E4 as an activator of $\gamma$-globin expression in humans (Jane et al. 1995; Zhao et al. 2006). It has been suggested that a short form of NF-E4 may have a role in repressing the $\gamma$-globin genes by inhibiting the normal activating function of NF-E4 at the promoter of these genes (Zhou et al. 2004). These studies have all been based on experiments performed in cultured cells and biochemical purification of protein complexes from K562 cells and therefore further work will be needed to confirm the physiological role of this gene in $\gamma$-globin expression and better understand the mechanisms through which this complex may be acting to alter human globin gene regulation.

\section{TRANSLATING THE INSIGHT FROM MOLECULAR STUDIES OF HbF REGULATION INTO THERAPIES}

The majority of molecules that have been identified as regulators of the fetal-to-adult hemoglobin switch and $\mathrm{HbF}$ silencing are transcription factors, including BCL11A, MYB, and KLF1 (Table 1). These proteins are notoriously difficult to target using traditional small molecule approaches (Koehler 2010). With the increasing diversity of chemical libraries that are being synthesized, it is possible that such small molecule modulators of these targets may be found (Dandapani and Marcaurelle 2010). An alternative and perhaps simpler approach, would involve targeting of enzymatic partner proteins of these transcription factors. For example, BCL11A appears to interact with the NuRD chromatin remodeling and repressor complex that contains HDACs 1 and 2 (Sankaran et al. 2008). A number of small molecule inhibitors of these molecules exist (Bradner et al. 2010), suggesting a potential strategy for indirectly targeting such factors. In addition, other epigenetic modifier enzymes, such as the DNA methyltransferase DNMT1, have been suggested to be potentially good targets for HbF induction, which is sup- ported by experiments using direct knockdown of the enzyme and from the known efficacy of 5azacytidine (Banzon et al. 2011). However, further mechanistic studies of these $\mathrm{HbF}$ regulators will be needed before such strategies can be successfully used.

Recent studies have suggested some other creative approaches to targeting transcription factors. One strategy involves the use of stapled peptides to inhibit transcription factor complexes by interfering with protein-protein interaction interfaces, as has been successfully performed for the NOTCH transcriptional complex involved in the pathogenesis of certain forms of leukemia (Moellering et al. 2009). An alternative strategy would be to target "druggable" molecules that would interfere with the expression of the target transcription factor. Recent work has shown that such a strategy can be successfully used to down-regulate expression of the oncogene $M Y C$ in a number of cancers by targeting a bromodomain protein necessary for its transcription (Delmore et al. 2011; Zuber et al. 2011b).

A more immediate strategy to target some of these transcription factors such as BCL11A, KLF1, or potentially MYB would be to use siRNA or shRNA delivery either through exogenous means or through the use of gene therapy approaches. The targeting of exogenous siRNAs to the desired cell type remains a major challenge, although ongoing advances in siRNA delivery suggest that specific approaches to target erythroid cells may be developed in the future (Leuschner et al. 2011). shRNAs targeting the transcriptional regulators of $\mathrm{HbF}$ expression could be introduced via gene therapy vectors (Wilber et al. 2011) and these may have advantages over introducing globin genes into hematopoietic cells because there is the potential for such approaches to both down-regulate the mutated adult $\beta$-globin molecule, while also upregulating endogenous $\gamma$-globin production.

Finally, once strategies to target these specific regulators of $\mathrm{HbF}$ expression are developed, it is possible that there may be synergistic interactions with existing inducers of $\mathrm{HbF}$. For example, combining hydroxyurea with specific targeting of factors such as BCL11A or MYB 
could lead to synergistic effects. Such a synergistic effect was observed when 5-azacytidine treatment was used in a BCL11A knockout mouse model ( $\mathrm{Xu}$ et al. 2011), suggesting that such strategies could potentially also be effective in humans. A great deal of additional work will be needed to explore what strategies may work best. Clearly innovation will be necessary for translating the knowledge gained about $\mathrm{HbF}$ regulation into therapies.

\section{CONCLUSIONS}

Here we have outlined historic and more recent studies that have provided insight into how the fetal-to-adult hemoglobin switch occurs and how HbF silencing can be manipulated. There is great promise that newer molecular studies will lead to targeted therapeutic approaches for $\mathrm{HbF}$ induction. However, as illustrated by historic work aimed at identifying $\mathrm{HbF}$ inducers, the path to effective therapies may not always be straightforward. Had it not been for studies questioning the original observation of the mechanism by which 5-azacytidine acted to induce $\mathrm{HbF}$ in primates and humans, hydroxyurea may not have been assessed and eventually found to be a clinically effective modulator of HbF levels in humans. Even with the increased understanding provided by more recent molecular studies, leading to promising therapeutic targets such as BCL11A, MYB, and KLF1, the best approach by which such molecules can be therapeutically manipulated remains unclear. It is likely that further studies of these and other molecules that regulate this process will lead to mechanistically based approaches for $\mathrm{HbF}$ induction. Trials targeting as many of these candidates as possible will eventually yield strategies that can be clinically effective, as it is difficult to predict a priori what strategies will work best. In addition to the basic science necessary for these translational efforts, a significant investment in clinical investigation will also be necessary, as it is still unclear what clinical end points are best to use in studying both existing and potentially newly developed therapies for $\mathrm{HbF}$ induction. However, this significant effort will be extremely worthwhile, because development of such strat- egies for $\mathrm{HbF}$ induction will be of broad importance for the numerous patients affected by sickle cell disease and $\beta$-thalassemia worldwide.

\section{ACKNOWLEDGMENTS}

We thank T. DiCesare for assistance in preparing illustrations. V.G.S. received support from $\mathrm{Na}-$ tional Institutes of Health grant T32 HL00757430 and from funding provided by Boston Children's Hospital. S.H.O. is an investigator of the Howard Hughes Medical Institute.

\section{REFERENCES}

Aerbajinai W, Zhu J, Kumkhaek C, Chin K, Rodgers GP. 2009. SCF induces $\gamma$-globin gene expression by regulating downstream transcription factor COUP-TFII. Blood 114: $187-194$.

Arnaud L, Saison C, Helias V, Lucien N, Steschenko D, Giarratana MC, Prehu C, Foliguet B, Montout L, de Brevern AG, et al. 2010. A dominant mutation in the gene encoding the erythroid transcription factor KLF1 causes a congenital dyserythropoietic anemia. Am J Hum Genet 87: 721-727.

Atweh G, Fathallah H. 2010. Pharmacologic induction of fetal hemoglobin production. Hematol Oncol Clin North Am 24: 1131-1144.

Banzon V, Ibanez V, Vaitkus K, Ruiz MA, Peterson K, DeSimone J, Lavelle D. 2011. siDNMT1 increases $\gamma$-globin expression in chemical inducer of dimerization (CID)-dependent mouse $\beta$ YAC bone marrow cells and in baboon erythroid progenitor cell cultures. Exp Hematol 39: 26-36 e21.

Bard H, Prosmanne J. 1985. Relative rates of fetal hemoglobin and adult hemoglobin synthesis in cord blood of infants of insulin-dependent diabetic mothers. Pediatrics 75: $1143-1147$.

Benz Jr. EJJr. 1982. Clinical management of gene expression. N Engl J Med 307: 1515-1516.

Borg J, Papadopoulos P, Georgitsi M, Gutierrez L, Grech G, Fanis P, Phylactides M, Verkerk AJ, van der Spek PJ, Scerri CA, et al. 2010. Haploinsufficiency for the erythroid transcription factor KLF1 causes hereditary persistence of fetal hemoglobin. Nat Genet 42: 801-805.

Bradner JE, Mak R, Tanguturi SK, Mazitschek R, Haggarty SJ, Ross K, Chang CY, Bosco J, West N, Morse E, et al. 2010. Chemical genetic strategy identifies histone deacetylase 1 (HDAC1) and HDAC2 as therapeutic targets in sickle cell disease. Proc Natl Acad Sci 107: 12617-12622.

Campbell AD, Cui S, Shi L, Urbonya R, Mathias A, Bradley K, Bonsu KO, Douglas RR, Halford B, Schmidt L, et al. 2011. Forced TR2/TR4 expression in sickle cell disease mice confers enhanced fetal hemoglobin synthesis and alleviated disease phenotypes. Proc Natl Acad Sci 108: 18808-18813. 
V.G. Sankaran and S.H. Orkin

Cantor AB, Orkin SH. 2002. Transcriptional regulation of erythropoiesis: An affair involving multiple partners. Oncogene 21: 3368-3376.

Cao H, Stamatoyannopoulos G, Jung M. 2004. Induction of human $\gamma$ globin gene expression by histone deacetylase inhibitors. Blood 103: 701-709.

Carpinelli MR, Hilton DJ, Metcalf D, Antonchuk JL, Hyland CD, Mifsud SL, Di Rago L, Hilton AA, Willson TA, Roberts AW, et al. 2004. Suppressor screen in $\mathrm{Mpl}^{-/-}$mice: $\mathrm{c}-\mathrm{Myb}$ mutation causes supraphysiological production of platelets in the absence of thrombopoietin signaling. Proc Natl Acad Sci 101: 6553-6558.

Castro O, Brambilla DJ, Thorington B, Reindorf CA, Scott RB, Gillette P, Vera JC, Levy PS. 1994. The acute chest syndrome in sickle cell disease: Incidence and risk factors. The Cooperative Study of Sickle Cell Disease. Blood 84: 643-649.

Cavazzana-Calvo M, Payen E, Negre O, Wang G, Hehir K, Fusil F, Down J, Denaro M, Brady T, Westerman K, et al. 2010. Transfusion independence and HMGA2 activation after gene therapy of human $\beta$-thalassaemia. Nature 467 : $318-322$.

Chakalova L, Osborne CS, Dai YF, Goyenechea B, Metaxotou-Mavromati A, Kattamis A, Kattamis C, Fraser P. 2005. The Corfu $\delta \beta$ thalassemia deletion disrupts $\gamma$-globin gene silencing and reveals post-transcriptional regulation of HbF expression. Blood 105: 2154-2160.

Charache S, Terrin ML, Moore RD, Dover GJ, Barton FB Eckert SV, McMahon RP, Bonds DR. 1995. Effect of hydroxyurea on the frequency of painful crises in sickle cell anemia. Investigators of the Multicenter Study of Hydroxyurea in Sickle Cell Anemia. N Engl J Med 332: 1317-1322.

Cui S, Kolodziej KE, Obara N, Amaral-Psarris A, Demmers J, Shi L, Engel JD, Grosveld F, Strouboulis J, Tanabe O. 2011. Nuclear receptors TR2 and TR4 recruit multiple epigenetic transcriptional corepressors that associate specifically with the embryonic $\beta$-type globin promoters in differentiated adult erythroid cells. Mol Cell Biol 31: 3298-3311.

Dandapani S, Marcaurelle LA. 2010. Current strategies for diversity-oriented synthesis. Curr Opin Chem Biol 14: 362-370.

Delmore JE, Issa GC, Lemieux ME, Rahl PB, Shi J, Jacobs HM, Kastritis E, Gilpatrick T, Paranal RM, Qi J, et al. 2011. BET bromodomain inhibition as a therapeutic strategy to target c-Myc. Cell 146: 904-917.

DeSimone J, Heller P, Hall L, Zwiers D. 1982. 5-Azacytidine stimulates fetal hemoglobin synthesis in anemic baboons. Proc Natl Acad Sci 79: 4428-4431.

Dumitriu B, Patrick MR, Petschek JP, Cherukuri S, Klingmuller U, Fox PL, Lefebvre V. 2006. Sox6 cell-autonomously stimulates erythroid cell survival, proliferation, and terminal maturation and is thereby an important enhancer of definitive erythropoiesis during mouse development. Blood 108: 1198-1207.

Emambokus N, Vegiopoulos A, Harman B, Jenkinson E, Anderson G, Frampton J. 2003. Progression through key stages of haemopoiesis is dependent on distinct threshold levels of c-Myb. Embo J 22: 4478-4488.

Fathallah H, Weinberg RS, Galperin Y, Sutton M, Atweh GF. 2007. Role of epigenetic modifications in normal globin gene regulation and butyrate-mediated induction of fetal hemoglobin. Blood 110: 3391-3397.

Filipe A, Li Q, Deveaux S, Godin I, Romeo PH, Stamatoyannopoulos G, Mignotte V. 1999. Regulation of embryonic/fetal globin genes by nuclear hormone receptors: A novel perspective on hemoglobin switching. EMBO J 18: 687-697.

Fritsch EF, Lawn RM, Maniatis T. 1980. Molecular cloning and characterization of the human $\beta$-like globin gene cluster. Cell 19: 959-972.

Galanello R, Sanna S, Perseu L, Sollaino MC, Satta S, Lai ME, Barella S, Uda M, Usala G, Abecasis GR, et al. 2009. Amelioration of Sardinian $\beta 0$ thalassemia by genetic modifiers. Blood 114: 3935-3937.

Galarneau G, Palmer CD, Sankaran VG, Orkin SH, Hirschhorn JN, Lettre G. 2010. Fine-mapping at three loci known to affect fetal hemoglobin levels explains additional genetic variation. Nat Genet 42: 1049-1051.

Gallienne AE, Dreau HM, Schuh A, Old J, Henderson S. 2012. Ten novel mutations in the erythroid transcription factor KLF1 gene associated with increased fetal hemoglobin levels in adults. Haematol 97: 340-343.

Groudine M, Eisenman R, Weintraub H. 1981. Chromatin structure of endogenous retroviral genes and activation by an inhibitor of DNA methylation. Nature 292: 311317.

Higgs DR, Wood WG. 2008. Genetic complexity in sickle cell disease. Proc Natl Acad Sci 105: 11595-11596.

Hsieh MM, Kang EM, Fitzhugh CD, Link MB, Bolan CD, Kurlander R, Childs RW, Rodgers GP, Powell JD, Tisdale JF. 2009. Allogeneic hematopoietic stem-cell transplantation for sickle cell disease. N Engl J Med 361: 2309-2317.

Huehns ER, Hecht F, Keil JV, Motulsky AG. 1964. Developmental hemoglobin anomalies in a chromosomal triplication: D1 trisomy syndrome. Proc Natl Acad Sci 51: 89-97.

Jane SM, Nienhuis AW, Cunningham JM. 1995. Hemoglobin switching in man and chicken is mediated by a heteromeric complex between the ubiquitous transcription factor $\mathrm{CP} 2$ and a developmentally specific protein. EMBO J 14: 97-105.

Jiang J, Best S, Menzel S, Silver N, Lai MI, Surdulescu GL, Spector TD, Thein SL. 2006. cMYB is involved in the regulation of fetal hemoglobin production in adults. Blood 108: 1077-1083.

Jones PA, Taylor SM. 1980. Cellular differentiation, cytidine analogs and DNA methylation. Cell 20: 85-93.

Kar BC, Satapathy RK, Kulozik AE, Kulozik M, Sirr S, Serjeant BE, Serjeant GR. 1986. Sickle cell disease in Orissa State, India. Lancet 2: 1198-1201.

Koehler AN. 2010. A complex task? Direct modulation of transcription factors with small molecules. Curr Opin Chem Biol 14: 331-340.

Lettre G, Sankaran VG, Bezerra MA, Araujo AS, Uda M, Sanna S, Cao A, Schlessinger D, Costa FF, Hirschhorn JN, et al. 2008. DNA polymorphisms at the BCL11A, HBS1LMYB, and $\beta$-globin loci associate with fetal hemoglobin levels and pain crises in sickle cell disease. Proc Natl Acad Sci 105: 11869-11874.

Letvin NL, Linch DC, Beardsley GP, McIntyre KW, Nathan DG. 1984. Augmentation of fetal-hemoglobin pro- 
duction in anemic monkeys by hydroxyurea. NEngl JMed 310: $869-873$.

Letvin NL, Linch DC, Beardsley GP, McIntyre KW, Miller BA, Nathan DG. 1985. Influence of cell cycle phase-specific agents on simian fetal hemoglobin synthesis. J Clin Invest 75: 1999-2005.

Leuschner F, Dutta P, Gorbatov R, Novobrantseva TI, Donahoe JS, Courties G, Lee KM, Kim JI, Markmann JF, Marinelli B, et al. 2011. Therapeutic siRNA silencing in inflammatory monocytes in mice. Nat Biotechnol 29: $1005-1010$.

Ley TJ, DeSimone J, Anagnou NP, Keller GH, Humphries RK, Turner PH, Young NS, Keller P, Nienhuis AW. 1982. 5Azacytidine selectively increases $\gamma$-globin synthesis in a patient with $\beta^{+}$thalassemia. NEnglJMed 307: 1469-1475.

Ley TJ, DeSimone J, Noguchi CT, Turner PH, Schechter AN, Heller P, Nienhuis AW. 1983. 5-Azacytidine increases $\gamma$ globin synthesis and reduces the proportion of dense cells in patients with sickle cell anemia. Blood 62: 370-380.

McGrath K, Palis J. 2008. Ontogeny of erythropoiesis in the mammalian embryo. Curr Top Dev Biol 82: 1-22.

McGrath KE, Frame JM, Fromm GJ, Koniski AD, Kingsley PD, Little J, Bulger M, Palis J. 2011. A transient definitive erythroid lineage with unique regulation of the $\beta$ globin locus in the mammalian embryo. Blood 117: 4600-4608.

Menzel S, Garner C, Gut I, Matsuda F, Yamaguchi M, Heath S, Foglio M, Zelenika D, Boland A, Rooks H, et al. 2007. A QTL influencing F cell production maps to a gene encoding a zinc-finger protein on chromosome 2p15. Nat Genet 39: 1197-1199.

Michlitsch JG, Walters MC. 2008. Recent advances in bone marrow transplantation in hemoglobinopathies. Curr Mol Med 8: 675-689.

Moellering RE, Cornejo M, Davis TN, Del Bianco C, Aster JC, Blacklow SC, Kung AL, Gilliland DG, Verdine GL, Bradner JE. 2009. Direct inhibition of the NOTCH transcription factor complex. Nature 462: 182-188.

Mukai HY, Motohashi H, Ohneda O, Suzuki N, Nagano M, Yamamoto M. 2006. Transgene insertion in proximity to the c-myb gene disrupts erythroid-megakaryocytic lineage bifurcation. Mol Cell Biol 26: 7953-7965.

Musallam KM, Sankaran VG, Cappellini MD, Duca L, Nathan DG, Taher AT. 2011. Fetal hemoglobin levels and morbidity in untransfused patients with $\beta$-thalassemia intermedia. Blood 119: 364-367.

Nuinoon M, Makarasara W, Mushiroda T, Setianingsih I, Wahidiyat PA, Sripichai O, Kumasaka N, Takahashi A, Svasti S, Munkongdee T, et al. 2010. A genome-wide association identified the common genetic variants influence disease severity in $\beta 0$-thalassemia/hemoglobin $\mathrm{E}$. Hum Genet 127: 303-314.

Pace B, Li Q, Peterson K, Stamatoyannopoulos G. 1994. $\alpha$ Amino butyric acid cannot reactivate the silenced $\gamma$ gene of the $\beta$ locus YAC transgenic mouse. Blood 84: 4344-4353.

Papayannopoulou T, Torrealba de Ron A, Veith R, Knitter G, Stamatoyannopoulos G. 1984. Arabinosylcytosine induces fetal hemoglobin in baboons by perturbing erythroid cell differentiation kinetics. Science 224: 617-619.

Perrine RP, Brown MJ, Clegg JB, Weatherall DJ, May A. 1972. Benign sickle-cell anaemia. Lancet 2: 1163-1167.
Perrine SP, Greene MF, Faller DV. 1985. Delay in the fetal globin switch in infants of diabetic mothers. N Engl J Med 312: 334-338.

Perrine SP, Ginder GD, Faller DV, Dover GH, Ikuta T, Witkowska HE, Cai SP, Vichinsky EP, Olivieri NF. 1993. A short-term trial of butyrate to stimulate fetal-globingene expression in the $\beta$-globin disorders. $N$ Engl J Med 328: $81-86$.

Perrine SP, Olivieri NF, Faller DV, Vichinsky EP, Dover GJ, Ginder GD. 1994. Butyrate derivatives. New agents for stimulating fetal globin production in the $\beta$-globin disorders. Am J Pediatr Hematol Oncol 16: 67-71.

Persons DA. 2009. Hematopoietic stem cell gene transfer for the treatment of hemoglobin disorders. Hematology 2009: 690-697.

Peschle C, Mavilio F, Care A, Migliaccio G, Migliaccio AR, Salvo G, Samoggia P, Petti S, Guerriero R, Marinucci M, et al. 1985. Haemoglobin switching in human embryos: Asynchrony of $\zeta \rightarrow \alpha$ and $\varepsilon \rightarrow \gamma$-globin switches in primitive and definite erythropoietic lineage. Nature 313: $235-238$.

Platt OS. 2008. Hydroxyurea for the treatment of sickle cell anemia. N Engl J Med 358: 1362-1369.

Platt OS, Orkin SH, Dover G, Beardsley GP, Miller B, Nathan DG. 1984. Hydroxyurea enhances fetal hemoglobin production in sickle cell anemia. J Clin Invest 74: 652-656.

Platt OS, Thorington BD, Brambilla DJ, Milner PF, Rosse WF, Vichinsky E, Kinney TR. 1991. Pain in sickle cell disease. Rates and risk factors. N Engl J Med 325: 11-16.

Platt OS, Brambilla DJ, Rosse WF, Milner PF, Castro O, Steinberg MH, Klug PP. 1994. Mortality in sickle cell disease. Life expectancy and risk factors for early death. N Engl J Med 330: 1639-1644.

Porter JB, Shah FT. 2010. Iron overload in thalassemia and related conditions: Therapeutic goals and assessment of response to chelation therapies. Hematol Oncol Clin North Am 24: 1109-1130.

Premawardhena A, Fisher CA, Olivieri NF, de Silva S, Arambepola M, Perera W, O'Donnell A, Peto TE, Viprakasit V, Merson L, et al. 2005. Haemoglobin E $\beta$ thalassaemia in Sri Lanka. Lancet 366: 1467-1470.

Sankaran VG, Nathan DG. 2010a. Reversing the hemoglobin switch. N Engl J Med 363: 2258-2260.

Sankaran VG, Nathan DG. 2010b. Thalassemia: An overview of 50 years of clinical research. Hematol Oncol Clin North Am 24: 1005-1020.

Sankaran VG, Sapp MV. 2012. Persistence of fetal hemoglobin expression in an older child with trisomy 13. J Pediatr 160: 352 .

Sankaran VG, Menne TF, Xu J, Akie TE, Lettre G, Van Handel B, Mikkola HK, Hirschhorn JN, Cantor AB, Orkin SH. 2008. Human fetal hemoglobin expression is regulated by the developmental stage-specific repressor BCL11A. Science 322: 1839-1842.

Sankaran VG, Xu J, Ragoczy T, Ippolito GC, Walkley CR, Maika SD, Fujiwara Y, Ito M, Groudine M, Bender MA, et al. 2009. Developmental and species-divergent globin switching are driven by BCL11A. Nature 460: 1093-1097. 
V.G. Sankaran and S.H. Orkin

Sankaran VG, Xu J, Orkin SH. 2010. Advances in the understanding of haemoglobin switching. Brit J Haematol 149: $181-194$.

Sankaran VG, Menne J, Heller R. 2011a. Heterozygous disruption of human SOX6 is insufficient to impair erythropoiesis or silencing of fetal hemoglobin. Blood 117: 4396-4397.

Sankaran VG, Menne TF, Scepanovic D, Vergilio JA, Ji P, Kim J, Thiru P, Orkin SH, Lander ES, Lodish HF. 2011b. MicroRNA-15a and -16-1 act via MYB to elevate fetal hemoglobin expression in human trisomy 13. Proc Natl Acad Sci 108: 1519-1524.

Sankaran VG, Xu J, Byron R, Greisman HA, Fisher C, Weatherall DJ, Sabath DE, Groudine M, Orkin SH, Premawardhena A, et al. 2011c. A functional element necessary for fetal hemoglobin silencing. $N$ Engl J Med 365: 807-814.

Satta S, Perseu L, Moi P, Asunis I, Cabriolu A, Maccioni L, Demartis FR, Manunza L, Cao A, Galanello R. 2011. Compound heterozygosity for KLF1 mutations associated with remarkable increase of fetal hemoglobin and red cell protoporphyrin. Haematologica 96: 767-770.

Sher GD, Ginder GD, Little J, Yang S, Dover GJ, Olivieri NF. 1995. Extended therapy with intravenous arginine butyrate in patients with $\beta$-hemoglobinopathies. $N$ Engl $J$ Med 332: 1606-1610.

Stadhouders R, Thongjuea S, Andrieu-Soler C, Palstra RJ, Bryne JC, van den Heuvel A, Stevens M, de Boer E, Kockx C, van der Sloot A, et al. 2011. Dynamic longrange chromatin interactions control Myb proto-oncogene transcription during erythroid development. $E M B O$ J31: 986-999.

Steinberg MH, Barton F, Castro O, Pegelow CH, Ballas SK, Kutlar A, Orringer E, Bellevue R, Olivieri N, Eckman J, et al. 2003. Effect of hydroxyurea on mortality and morbidity in adult sickle cell anemia: Risks and benefits up to 9 years of treatment. JAMA 289: 1645-1651.

Tanabe O, Katsuoka F, Campbell AD, Song W, Yamamoto M, Tanimoto K, Engel JD. 2002. An embryonic/fetal $\beta$-type globin gene repressor contains a nuclear receptor TR2/ TR4 heterodimer. EMBO J 21: 3434-3442.

Tanabe O, McPhee D, Kobayashi S, Shen Y, Brandt W, Jiang X, Campbell AD, Chen YT, Chang C, Yamamoto M, et al. 2007. Embryonic and fetal $\beta$-globin gene repression by the orphan nuclear receptors, TR2 and TR4. EMBO J 26: $2295-2306$.

Thein SL, Menzel S, Peng X, Best S, Jiang J, Close J, Silver N, Gerovasilli A, Ping C, Yamaguchi M, et al. 2007. Intergenic variants of HBS1L-MYB are responsible for a major quantitative trait locus on chromosome 6q23 influencing fetal hemoglobin levels in adults. Proc Natl Acad Sci 104: 11346-11351.

Uda M, Galanello R, Sanna S, Lettre G, Sankaran VG, Chen W, Usala G, Busonero F, Maschio A, Albai G, et al. 2008. Genome-wide association study shows BCL11A associated with persistent fetal hemoglobin and amelioration of the phenotype of $\beta$-thalassemia. Proc Natl Acad Sci 105: 1620-1625.

van der Ploeg LH, Flavell RA. 1980. DNA methylation in the human $\gamma \delta \beta$-globin locus in erythroid and nonerythroid tissues. Cell 19: 947-958. van Dijk TB, Gillemans N, Pourfarzad F, van Lom K, von Lindern M, Grosveld F, Philipsen S. 2010. Fetal globin expression is regulated by Friend of Prmt1. Blood 116: 4349-4352.

Wahlberg K, Jiang J, Rooks H, Jawaid K, Matsuda F, Yamaguchi M, Lathrop M, Thein SL, Best S. 2009. The HBS1L-MYB intergenic interval associated with elevated HbF levels shows characteristics of a distal regulatory region in erythroid cells. Blood 114: 1254-1262.

Watson J. 1948. The significance of the paucity of sickle cells in newborn Negro infants. Am J Med Sci 215: 419-423.

Weatherall DJ. 2001. Phenotype-genotype relationships in monogenic disease: Lessons from the thalassaemias. Nat Rev 2: $245-255$.

Weatherall DJ, Clegg JB. 2001. The thalassaemia syndromes, 4th ed. Blackwell Science, Malden, MA.

Weatherall D, Akinyanju O, Fucharoen S, Olivieri N, Musgrove P. 2006. Inherited disorders of hemoglobin. In Disease control priorities in developing countries, 2nd ed., pp. 663-680. Oxford University Press, New York.

Wilber A, Hargrove PW, Kim YS, Riberdy JM, Sankaran VG, Papanikolaou E, Georgomanoli M, Anagnou NP, Orkin SH, Nienhuis AW, et al. 2011. Therapeutic levels of fetal hemoglobin in erythroid progeny of $\beta$-thalassemic $\mathrm{CD} 34^{+}$cells after lentiviral vector-mediated gene transfer. Blood 117: 2817-2826.

Xu J, Sankaran VG, Ni M, Menne TF, Puram RV, Kim W, Orkin SH. 2010. Transcriptional silencing of $\gamma$-globin by BCL11A involves long-range interactions and cooperation with SOX6. Genes Dev 24: 783-798.

Xu J, Peng C, Sankaran VG, Shao Z, Esrick EB, Chong BG, Ippolito GC, Fujiwara Y, Ebert BL, Tucker PW, et al. 2011. Correction of sickle cell disease in adult mice by interference with fetal hemoglobin silencing. Science 334: $993-$ 996.

Zhao Q, Zhou W, Rank G, Sutton R, Wang X, Cumming H, Cerruti L, Cunningham JM, Jane SM. 2006. Repression of human $\gamma$-globin gene expression by a short isoform of the NF-E4 protein is associated with loss of NF-E2 and RNA polymerase II recruitment to the promoter. Blood 107: $2138-2145$.

Zhou W, Zhao Q, Sutton R, Cumming H, Wang X, Cerruti L, Hall M, Wu R, Cunningham JM, Jane SM. 2004. The role of p22 NF-E4 in human globin gene switching. J Biol Chem 279: 26227-26232.

Zhou D, Liu K, Sun CW, Pawlik KM, Townes TM. 2010. KLF1 regulates BCL11A expression and $\gamma$ - to $\beta$-globin gene switching. Nat Genet 42: 742-744.

Zuber J, Rappaport AR, Luo W, Wang E, Chen C, Vaseva AV, Shi J, Weissmueller S, Fellmann C, Taylor MJ, et al. 2011a. An integrated approach to dissecting oncogene addiction implicates a Myb-coordinated self-renewal program as essential for leukemia maintenance. Genes Dev 25: $1628-1640$.

Zuber J, Shi J, Wang E, Rappaport AR, Herrmann H, Sison EA, Magoon D, Qi J, Blatt K, Wunderlich M, et al. 2011b. RNAi screen identifies Brd4 as a therapeutic target in acute myeloid leukaemia. Nature 478: 524-528.

Zuk O, Hechter E, Sunyaev SR, Lander ES. 2012. The mystery of missing heritability: Genetic interactions create phantom heritability. Proc Natl Acad Sci 109: 1193-1198. 


\section{$\&_{\mathrm{CSH}}^{\infty} \&$ Cold Spring Harbor

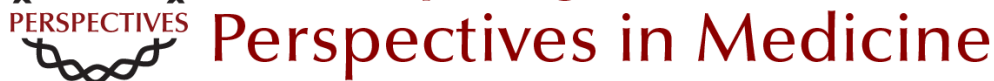

\section{The Switch from Fetal to Adult Hemoglobin}

Vijay G. Sankaran and Stuart H. Orkin

Cold Spring Harb Perspect Med 2013; doi: 10.1101/cshperspect.a011643 originally published online December 3, 2012

\section{Subject Collection Hemoglobin and Its Diseases}

The Natural History of Sickle Cell Disease Graham R. Serjeant

\section{Current Management of Sickle Cell Anemia} Patrick T. McGann, Alecia C. Nero and Russell E. Ware

Cell-Free Hemoglobin and Its Scavenger Proteins:

New Disease Models Leading the Way to Targeted Therapies

Dominik J. Schaer and Paul W. Buehler

Clinical Manifestations of $\alpha$-Thalassemia Elliott P. Vichinsky

Erythroid Heme Biosynthesis and Its Disorders Harry A. Dailey and Peter N. Meissner

Hemoglobin Variants: Biochemical Properties and Clinical Correlates Christopher S. Thom, Claire F. Dickson, David A. Gell, et al.

The Prevention of Thalassemia Antonio Cao and Yuet Wai Kan

The Switch from Fetal to Adult Hemoglobin Vijay G. Sankaran and Stuart H. Orkin
Transcriptional Mechanisms Underlying Hemoglobin Synthesis

Koichi R. Katsumura, Andrew W. DeVilbiss, Nathaniel J. Pope, et al.

Iron Deficiency Anemia: A Common and Curable Disease Jeffery L. Miller

Management of the Thalassemias Nancy F. Olivieri and Gary M. Brittenham

The Molecular Basis of $\beta$-Thalassemia Swee Lay Thein

Erythropoiesis: Development and Differentiation Elaine Dzierzak and Sjaak Philipsen

Erythropoietin

H. Franklin Bunn

Classification of the Disorders of Hemoglobin Bernard G. Forget and H. Franklin Bunn

The Molecular Basis of $\alpha$-Thalassemia Douglas R. Higgs

For additional articles in this collection, see http://perspectivesinmedicine.cshlp.org/cgi/collection/ 